\title{
PENGARUH SUKARELAWAN PENGATUR LALU LINTAS TERHADAP KINERJA SIMPANG TAK BERSINYAL GANESHA SURAKARTA
}

\author{
Gus Maelan Irfana \\ Prodi Teknik Sipil \\ Fakultas Teknik \\ Universitas Muhammadiyah \\ Surakarta \\ gusmaelanirfana@gmail.com
}

\author{
Nurul Hidayati \\ Prodi Magister Teknik Sipil \\ Sekolah Pascasarjana \\ Universitas Muhammadiyah \\ Surakarta \\ Nurul.Hidayati@ums.ac.id
}

\author{
Sri Sunarjono \\ Prodi Magister Teknik Sipil \\ Sekolah Pascasarjana \\ Universitas Muhammadiyah \\ Surakarta \\ Sri.Sunarjono@ums.ac.id
}

\begin{abstract}
Traffic congestion in the City of Surakarta gave rise to a phenomenal figure among motor vehicle drivers, called the Traffic Control Volunteers or abbreviated as Supeltas. This Supeltas is present on the road to help organize the movement of traffic, as happened at the Surakarta Ganesha Unsignalized Intersection. This study aims to determine the influence of the existence of Supeltas on capacity, degree of saturation, delay, and queuing opportunities that occur at the intersection. The analysis was carried out using the 1997 Indonesian Highway Capacity Manual. The results showed that the intersection without Supeltas had a capacity of 3,114.03 pcu/hour and a degree of saturation of 1.47 , while the same intersection but with Supeltas had a capacity of $3,136.81$ $\mathrm{pcu} /$ hour and a degree of saturation of 1.51. These results indicate that Supeltas has a positive influence on the performance of the intersection. Nevertheless, the degree of saturation in the location increased due to the increase in traffic volume as well as increased capacity.
\end{abstract}

Keywords: unsignalized intersection, intersection performance, intersection capacity, degree of saturation

\begin{abstract}
Abstrak
Kemacetan lalu lintas di Kota Surakarta memunculkan sosok fenomenal di kalangan pengendara kendaraan bermotor, yang disebut Sukarelawan Pengatur Lalu Lintas atau disingkat Supeltas. Supeltas ini hadir di jalan untuk membantu mengatur pergerakan lalu lintas, seperti yang terjadi di Simpang Tak Bersinyal Ganesha Surakarta. Penelitian ini bertujuan untuk menentukan pengaruh keberadaan Supeltas terhadap kapasitas, derajat kejenuhan, tundaan, dan peluang antrian yang terjadi di simpang tersebut. Analisis dilakukan dengan menggunakan Manual Kapasitas Jalan Indonesia 1997. Hasil analisis menunjukkan bahwa simpang tanpa Supeltas memiliki kapasitas sebesar 3.114,03 smp/jam dan derajat kejenuhan 1,47, sedangkan simpang yang sama tetapi dengan Supeltas memiliki kapasitas sebesar 3.136,81 smp/jam dan derajat kejenuhan 1,51. Hasil tersebut menunjukkan bahwa Supeltas mempunyai pengaruh positif terhadap kinerja simpang. Meskipun demikian, derajat kejenuhan di lokasi tersebut meningkat karena bertambahnya volume lalu lintas di samping kapasitas yang juga meningkat.
\end{abstract}

Kata-kata kunci: simpang tak bersinyal, kinerja simpang, kapasitas simpang, derajat kejenuhan

\section{PENDAHULUAN}

Surakarta merupakan suatu kota yang memiliki daya tarik, seperti budaya dan kesenian, yang menjadi salah satu tujuan liburan bagi wisatawan domestik dan mancanegara. Meningkatnya arus wisatawan menunjukkan bahwa Surakarta menjadi tempat favorit untuk menghabiskan waktu liburan (Primasari, 2014). Kondisi tersebut menyebabkan adanya peningkatan 
kepadatan lalu lintas. Hal ini terlihat pada kemacetan lalu lintas di beberapa titik di Surakarta yang menganggu pergerakan lalu lintas (Rudatyo dan Hafid, 2017).

Masalah kemacetan lalu lintas sering terjadi di daerah yang memiliki jumlah penduduk tinggi dengan intensitas kegiatan yang tinggi pula. Kemacetan lalu lintas dapat terjadi karena volume lalu lintas yang tinggi tidak didukung dengan jaringan jalan yang memadai. Timbulnya kemacetan akan berpengaruh pada penggunaan sumber daya, misalnya meningkatnya pemakaian bahan bakar, dan mengganggu kondisi lingkungan sekitarnya (Mustikarani dan Suherdiyanto, 2016). Kemacetan mulai terlihat ketika rasio antara volume dan kapasitas lebih besar dari 0,8. Jika nilai tersebut telah mencapai nilai maksimalnya, arus lalu lintas menjadi tidak stabil, sehingga terjadi tundaan yang sangat parah (Tamin dan Nahdalina, 1998).

Selain volume lalu lintas, tingginya frekuensi kejadian hambatan samping juga dapat menyebabkan kemacetan. Hambatan samping tersebut termasuk segala macam kegiatan di pinggir jalan, baik di bahu jalan atau di trotoar, yang dapat memengaruhi pergerakan lalu lintas (Hidayati et al., 2012). Manajemen lalu lintas yang kurang optimal juga berdampak pada kemacetan yang terjadi. Usaha yang dilakukan untuk mengatur lalu lintas adalah merencanakan pergerakan kendaraan secara efisien, termasuk di antaranya adalah dengan melakukan rekayasa lalu lintas, memperbaiki transportasi umum, dan membuat kebijakan road pricing (Munawar, 2004).

Menurut Wismabrata (2017), setidaknya ada 14 titik kemacetan yang harus diwaspadai oleh pengguna jalan di Kota Surakarta atau Kota Solo. Beberapa titik kemacetan tersebut adalah Mall Solo Square dan Solo Grand Mall di Jln. Slamet Riyadi, perlintasan sebidang Pasar Nongko, Manahan, Purwosari, dan Joglo, serta kawasan Coyudan.

Adanya kemacetan lalu lintas memunculkan sosok fenomenal di kalangan pengendara bermotor, yaitu Sukarelawan Pengatur Lalu Lintas atau disingkat Supeltas. Supeltas ini hadir di jalan untuk membantu mengatur arus lalu lintas secara sukarela di beberapa tempat, termasuk di persimpangan yang tidak bersinyal.

Di Kota Solo, Supeltas menjadi sorotan publik karena perannya membantu dalam mengatasi kemacetan. Namun di sisi lain, ada hal lain yang muncul terkait dengan sukarela. Beberapa pengguna jalan mengatakan bahwa Supeltas memprioritaskan pengguna jalan yang memberi mereka bayaran. Selain itu, Supeltas juga dianggap sebagai salah satu penyebab kemacetan karena dianggap tidak memahami aturan lalu lintas. Penelitian ini dilakukan untuk mengetahui dampak Supeltas terhadap kinerja Simpang Tak Bersinyal Ganesha di Ngemplak, Surakarta. Lokasi ini dipilih karena kemacetan sering terjadi di simpang tersebut hingga mencapai Simpang Kandang Sapi.

Studi ini menggunakan data primer dan data sekunder. Data primer terdiri atas data geometri, traffic counting, dan hambatan samping. Survei data primer dilakukan pada tanggal 18 dan 25 September 2018. Lokasi penelitian dapat dilihat pada Gambar 1. 


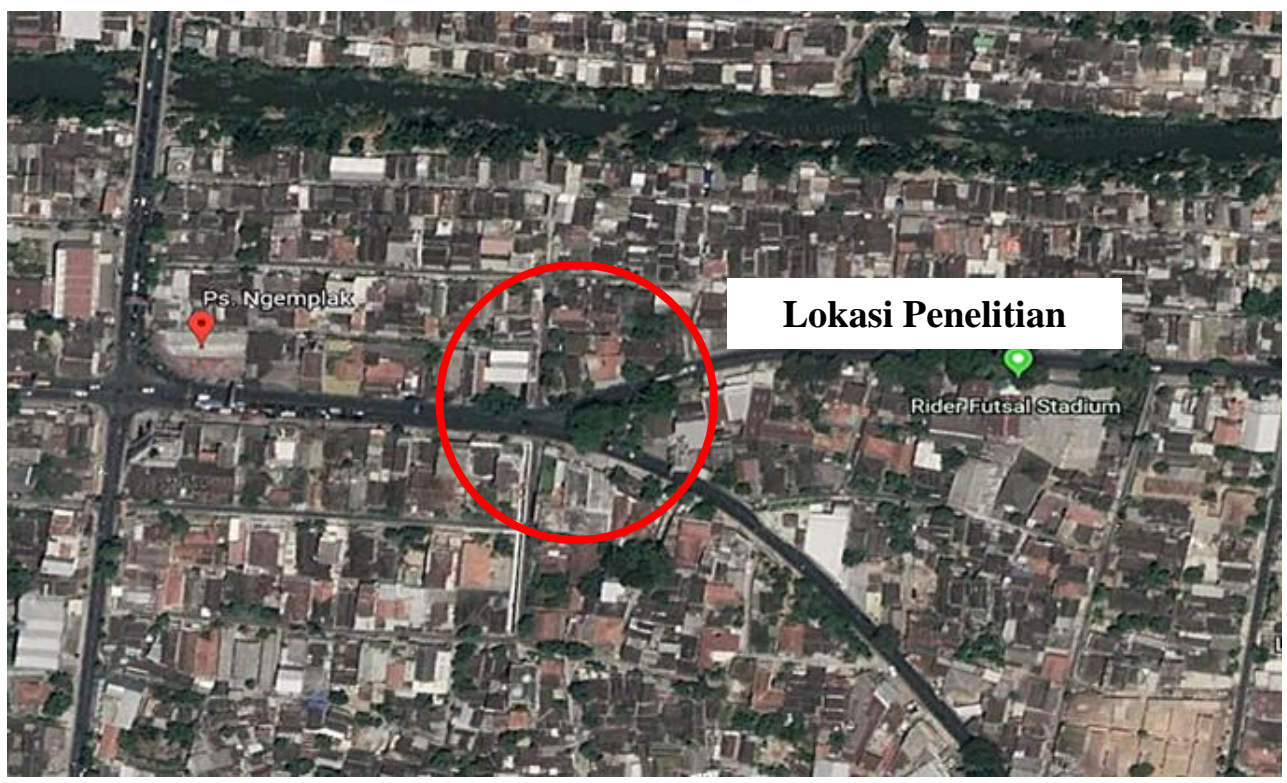

Gambar 1 Lokasi Penelitian

Analisis dilakukan dengan menggunakan Manual Kapasitas Jalan Indonesia 1997. Dari analisis ini diperoleh kapasitas (C), derajat kejenuhan (DS), tundaan (D), dan peluang antrian (QP).

\section{Kapasitas (C)}

Kapasitas simpang adalah arus maksimum yang dapat ditampung oleh simpang pada kondisi tertentu. Nilai kapasitas (dalam smp/jam) dihitung menggunakan Persamaan 1 (MKJI, 1997).

$$
\mathrm{C}=\mathrm{C}_{\mathrm{o}} \times \mathrm{F}_{\mathrm{W}} \times \mathrm{F}_{\mathrm{M}} \times \mathrm{F}_{\mathrm{CS}} \times \mathrm{F}_{\mathrm{RSU}} \times \mathrm{F}_{\mathrm{LT}} \times \mathrm{F}_{\mathrm{RT}} \times \mathrm{F}_{\mathrm{MI}}
$$

dengan:

$\mathrm{C}_{0} \quad=$ Kapasitas dasar (smp/jam);

$\mathrm{FW}=$ Faktor penyesuaian kapasitas terhadap rata-rata lebar pendekat;

$\mathrm{F}_{\mathrm{M}}=$ Faktor penyesuaian kapasitas berdasarkan median pada jalur utama;

$\mathrm{F}_{\mathrm{cs}}=$ Faktor penyesuaian kapasitas terhadap ukuran kota;

$\mathrm{F}_{\mathrm{RSU}}=$ Faktor penyesuaian kapasitas berdasarkan kondisi lingkungan, hambatan samping, dan kendaraan tak bermotor;

$\mathrm{F}_{\mathrm{LT}}=$ Faktor penyesuaian kapasitas berdasarkan kendaraan belok kiri;

$\mathrm{F}_{\mathrm{RT}}=$ Faktor penyesuaian kapasitas berdasarkan kendaraan belok kanan; dan

$\mathrm{F}_{\mathrm{MI}}=$ Faktor penyesuaian kapasitas berdasarkan arus lalu lintas jalur minor.

\section{Derajat Kejenuhan (DS)}

Menurut MKJI (1997), derajat kejenuhan adalah rasio arus lalu lintas (Q, smp/jam) terhadap kapasitas (C, smp/jam). Nilai derajat kejenuhan dihitung menggunakan Persamaan 2:

$$
\mathrm{DS}=\mathrm{Q} / \mathrm{C}
$$




\section{Tundaan (D)}

Tundaan adalah pertambahan waktu perjalanan pada suatu perjalanan dari kondisi tanpa hambatan dibandingkan dengan adanya hambatan. Hambatan yang tersebut dapat berasal dari kondisi geometrik dan/atau dari kondisi lalu lintasnya. Beberapa parameter tundaan yang dicari dalam simpang tak bersinyal dapat dilihat pada Tabel 1.

Tabel 1 Tundaan

\begin{tabular}{|c|c|}
\hline Tipe Tundaan & Rumus \\
\hline Tundaan lalu lintas $\left(\mathrm{DT}_{1}\right)$ & $\begin{array}{l}2+8,2078 * \mathrm{DS}-(1-\mathrm{DS}) * 2 \mathrm{DS} \leq 0,6 \text { untuk DS } \leq 0,6 \\
1,0504 /(0,2742-0,2042 * \mathrm{DS})-(1-\mathrm{DS}) * 2 \text { untuk DS } \geq 0,6\end{array}$ \\
\hline Tundaan jalan utama (DT $\mathrm{MA}_{\mathrm{MA}}$ & $\begin{array}{l}1,8+5,8234 * \mathrm{DS}-(1-\mathrm{DS}) * 1,8 \mathrm{DS} \leq 0,6 \text { untuk DS } \leq 0,6 \\
1,05034 /(0,346-0,246 * \mathrm{DS})-(1-\mathrm{DS}) * 1,8 \text { untuk } \mathrm{DS} \leq 0,6\end{array}$ \\
\hline Tundaan jalan minor $\left(\mathrm{DT}_{\mathrm{MI}}\right)$ & $\left(\mathrm{Q}_{\mathrm{TOT}} \times \mathrm{DT}_{\mathrm{I}}-\mathrm{Q}_{\mathrm{MA}} \times \mathrm{DT}_{\mathrm{MA}}\right) / \mathrm{Q}_{\mathrm{MI}}$ \\
\hline Tundaan geometri (DG) & $\begin{array}{l}4 \text { untuk DS } \geq 1 \\
(1-\mathrm{DS}) *(\mathrm{Pt} .6+(1-\mathrm{Pt}) .3)+\mathrm{DS} * 4 \text { untuk DS } \leq 1\end{array}$ \\
\hline Tundaan simpang & $\mathrm{DG}+\mathrm{DT}_{1}$ \\
\hline
\end{tabular}

Sumber: Direktorat Jenderal Bina Marga (1997)

\section{Peluang Antrian (QP)}

Peluang antrian adalah kemungkinan terjadinya antrian kendaraan pada suatu simpang. Nilai peluang antrian dinyatakan sebagai kisaran (range) yang didapat dari hubungan antara derajat kejenuhan dan peluang antrian dengan persamaan ditampilkan pada Persamaan 10 dan Persamaan 11.

Nilai batas atas $=47,71 \mathrm{DS}-24,68 \mathrm{DS}^{2}+56,47 \mathrm{DS}^{3}$
Nilai batas bawah $=9,02 \mathrm{DS}+20,66 \mathrm{DS}^{2}+10,49 \mathrm{DS}^{3}$

\section{HASIL DAN PEMBAHASAN}

\section{Geometrik Simpang}

Data geometrik Simpang Ganesha Surakarta serta kondisi sekitarnya ditampilkan pada Tabel 2 dan Gambar 2.

Tabel 2 Geometri Simpang

\begin{tabular}{cccc}
\hline Nama Jalan & $\begin{array}{c}\text { Lebar Jalan } \\
(\mathrm{m})\end{array}$ & $\begin{array}{c}\text { Lebar Pendekat } \\
(\mathrm{m})\end{array}$ & Jumlah Lajur \\
\hline Jalan Nasional Barat & 12,22 & 6,52 & 2 \\
Jalan Nasional Timur & 6,72 & 3,41 & 2 \\
Jalan Tentara Pelajar & 6,64 & 3,36 & 2 \\
\hline
\end{tabular}

\section{Hambatan Samping}

Aktivitas samping jalan yang ditinjau meliputi pejalan kaki, kendaraan parkir atau berhenti, kendaraan keluar masuk jalur, dan kendaraan lambat. Hasil analisis hambatan samping dapat dilihat pada Tabel 3. Berdasarkan Tabel 3, dapat diketahui puncak hambatan samping setiap periode. Nilai puncak ditentukan berdasarkan jam puncak volume lalu lintas. 
Pada periode I, nilai puncak hambatan samping adalah 2027,3 frekuensi berbobot/jam pada 06.25-07.25. Pada periode II, nilai puncak hambatan samping adalah 674,6 frekuensi berbobot/jam pada 16.00-17.00. Pada periode III, diperoleh nilai 734,6 frekuensi berbobot/jam pada 06.35-07.35. Sementara, pada periode IV, diperoleh nilai 562,8 frekuensi berbobot/jam pada pukul 16.00-17.00. Perbedaan nilai tersebut terjadi karena perbedaan jumlah kendaraan yang keluar dan masuk gang di area sekitar persimpangan.

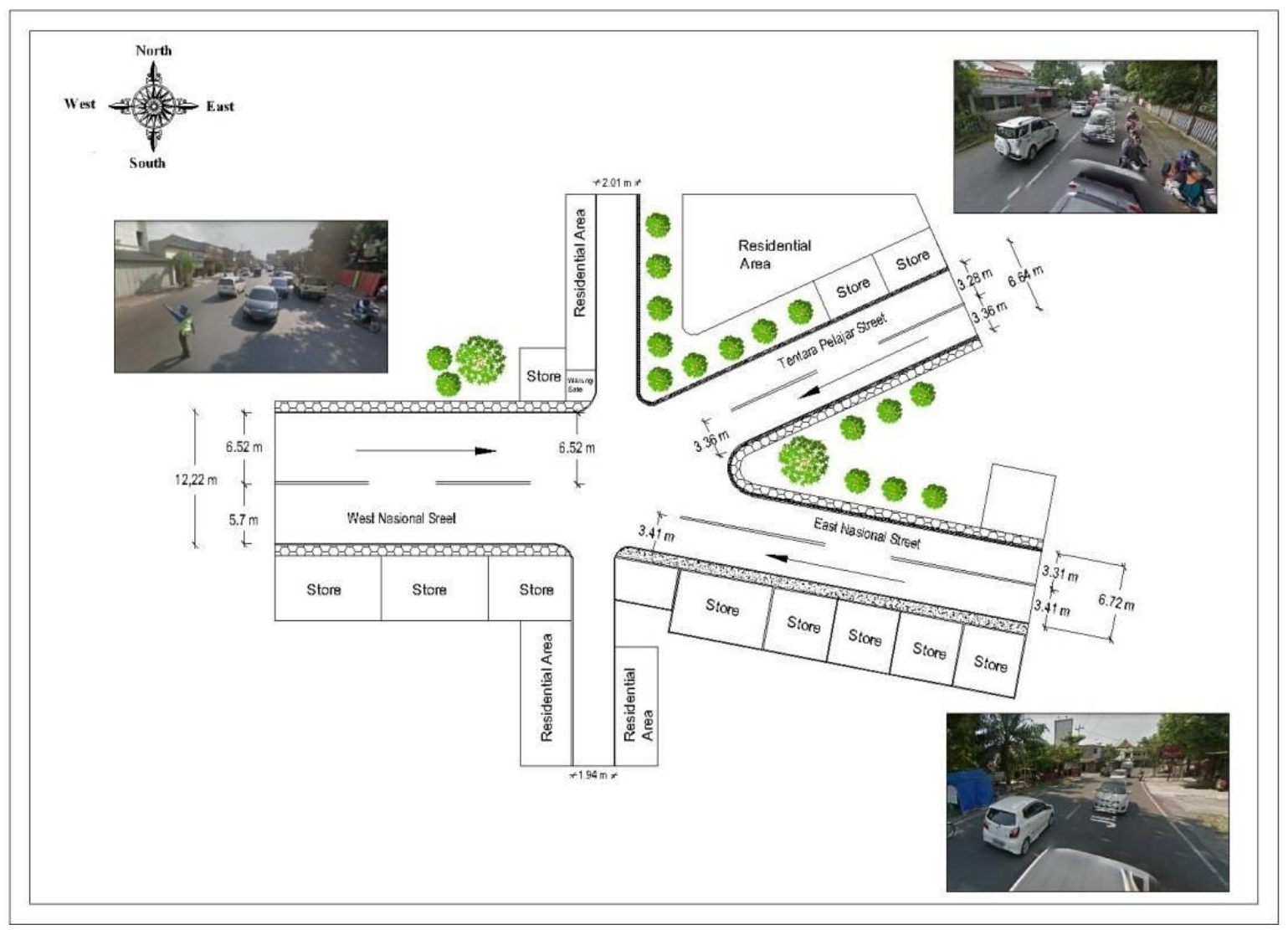

Gambar 2 Detail Geometri Simpang Ganesha

\section{Volume Lalu Lintas}

Volume lalu lintas diperoleh dengan cara survei di lokasi. Jenis kendaraan yang disurvei adalah sepeda motor, mobil, pick up, minibus, bus, truk, dan kendaraan tak bermotor. Hasil analisis volume lalu lintas dapat dilihat pada Gambar 3 dan Gambar 4.

Pada Gambar 3 terlihat perbedaan volume lalu lintas pada jam puncak. Pada periode I, jam puncak terjadi pada 06.25-07.25, dengan volume sebesar 4584,2 smp/jam. Sedangkan pada periode III, jam puncak terjadi pada 06.35-07.35, dengan volume sebesar $4742 \mathrm{smp} / \mathrm{jam}$. Volume lalu lintas pada periode III lebih tinggi daripada volume lalu lintas pada periode I. Hasil lain yang ditampilkan pada Gambar 4 menunjukkan bahwa jam puncak periode II dan periode IV terjadi pada saat yang sama, yaitu pukul 16.00-17.00. Pada periode II, jam puncak terjadi pada 06.25-07.25, dengan volume sebesar 3792,32 smp/jam, sementara pada periode IV, volume lalu lintas adalah 3415,22 smp/jam. 
Tabel 3 Hambatan Samping

\begin{tabular}{|c|c|c|c|c|c|c|c|c|}
\hline \multirow{3}{*}{ Waktu } & \multicolumn{8}{|c|}{ Hambatan Samping Per Jam Setiap Periode } \\
\hline & \multicolumn{4}{|c|}{18 September 2018} & \multicolumn{4}{|c|}{25 September 2018} \\
\hline & $\begin{array}{l}\text { Nasional } \\
\text { Timur }\end{array}$ & $\begin{array}{c}\text { Nasional } \\
\text { Barat }\end{array}$ & $\begin{array}{l}\text { Tentara } \\
\text { Pelajar }\end{array}$ & Total & $\begin{array}{l}\text { Nasional } \\
\text { Timur }\end{array}$ & $\begin{array}{c}\text { Nasional } \\
\text { Barat }\end{array}$ & $\begin{array}{l}\text { Tentara } \\
\text { Pelajar }\end{array}$ & Total \\
\hline $06.00-07.00$ & 108,5 & 1161,6 & 161,7 & 1431,8 & 109,3 & 372,5 & 200 & 681,8 \\
\hline 06.05-07.05 & 111,8 & 1322,9 & 178,5 & 1613,2 & 113,1 & 390,5 & 206,8 & 710,4 \\
\hline $06.10-07.10$ & 121,1 & 1435,1 & 182,1 & 1738,3 & 120 & 405,8 & 220,8 & 746,6 \\
\hline $06.15-07.15$ & 115,9 & 1548,3 & 181,3 & 1845,5 & 121,8 & 415,1 & 220,3 & 757,2 \\
\hline $06.20-07.20$ & 115,9 & 1618,2 & 180,7 & 1914,8 & 116,3 & 418,2 & 213,1 & 747,6 \\
\hline $06.25-07.25$ & 114,7 & 1731,7 & 180,9 & 2027,3 & 115,9 & 414,5 & 212,4 & 742,8 \\
\hline $06.30-07.30$ & 115,2 & 1800,7 & 182,9 & 2098,8 & 119,4 & 413 & 213,8 & 746,2 \\
\hline $06.35-07.35$ & 113,4 & 1920 & 188,9 & 2222,3 & 119,3 & 413 & 202,3 & 734,6 \\
\hline $06.40-07.40$ & 117,9 & 1980,1 & 193,5 & 2291,5 & 119,7 & 400,8 & 196,3 & 716,8 \\
\hline $06.45-07.45$ & 109,8 & 1911,8 & 215 & 2236,6 & 117,6 & 378,1 & 194,6 & 690,3 \\
\hline $06.50-07.50$ & 105,9 & 1791 & 204,8 & 2101,7 & 109,6 & 351,4 & 181 & 642 \\
\hline $06.55-07.55$ & 104,8 & 1729,3 & 200 & 2034,1 & 102,1 & 347,1 & 172,5 & 621,7 \\
\hline $07.00-08.00$ & 112,1 & 1615,2 & 203,3 & 1930,6 & 102 & 339,5 & 165,4 & 606,9 \\
\hline $16.00-17.00$ & 174,1 & 292,5 & 208 & 674,6 & 83,3 & 252,3 & 227,2 & 562,8 \\
\hline $16.05-17.05$ & 183,7 & 301,6 & 206,6 & 691,9 & 86,1 & 263 & 223,7 & 572,8 \\
\hline $16.10-17.10$ & 195,9 & 317,4 & 205,5 & 718,8 & 87,8 & 268,1 & 223,7 & 579,6 \\
\hline $16.15-17.15$ & 191,8 & 324,3 & 201,9 & 718 & 82,4 & 276,9 & 224,9 & 584,2 \\
\hline $16.20-17.20$ & 194,7 & 329,1 & 208,1 & 731,9 & 83,3 & 290,3 & 229,8 & 603,4 \\
\hline $16.25-17.25$ & 201,1 & 324,1 & 207,8 & 733 & 76,1 & 287,9 & 218,3 & 582,3 \\
\hline $16.30-17.30$ & 193 & 331,7 & 208,1 & 732,8 & 65,7 & 284,8 & 206,9 & 557,4 \\
\hline $16.35-17.35$ & 188,8 & 310,7 & 197,2 & 696,7 & 59,2 & 281,2 & 190,2 & 530,6 \\
\hline $16.40-17.40$ & 186,4 & 291 & 169 & 646,4 & 56,3 & 269,2 & 181,5 & 507 \\
\hline $16.45-17.45$ & 179,8 & 276,9 & 168,6 & 625,3 & 55,2 & 259,7 & 186,4 & 501,3 \\
\hline $16.50-17.50$ & 182,1 & 262,6 & 169,3 & 614 & 51,3 & 243,8 & 190,5 & 485,6 \\
\hline $16.55-17.55$ & 188,1 & 262,7 & 171,1 & 621,9 & 54,8 & 235,2 & 183,3 & 473,3 \\
\hline $17.00-18.00$ & 184,1 & 267,9 & 165,3 & 617,3 & 54,9 & 230,2 & 193,4 & 478,5 \\
\hline
\end{tabular}

Catatan: Periode I, pukul 06.00-08.00 dan Periode II, pukul 16.00-18.00 Tanpa Supeltas Periode III, pukul 06.00-08.00 dan Periode IV, pukul 16.00-18.00 Ada Supeltas

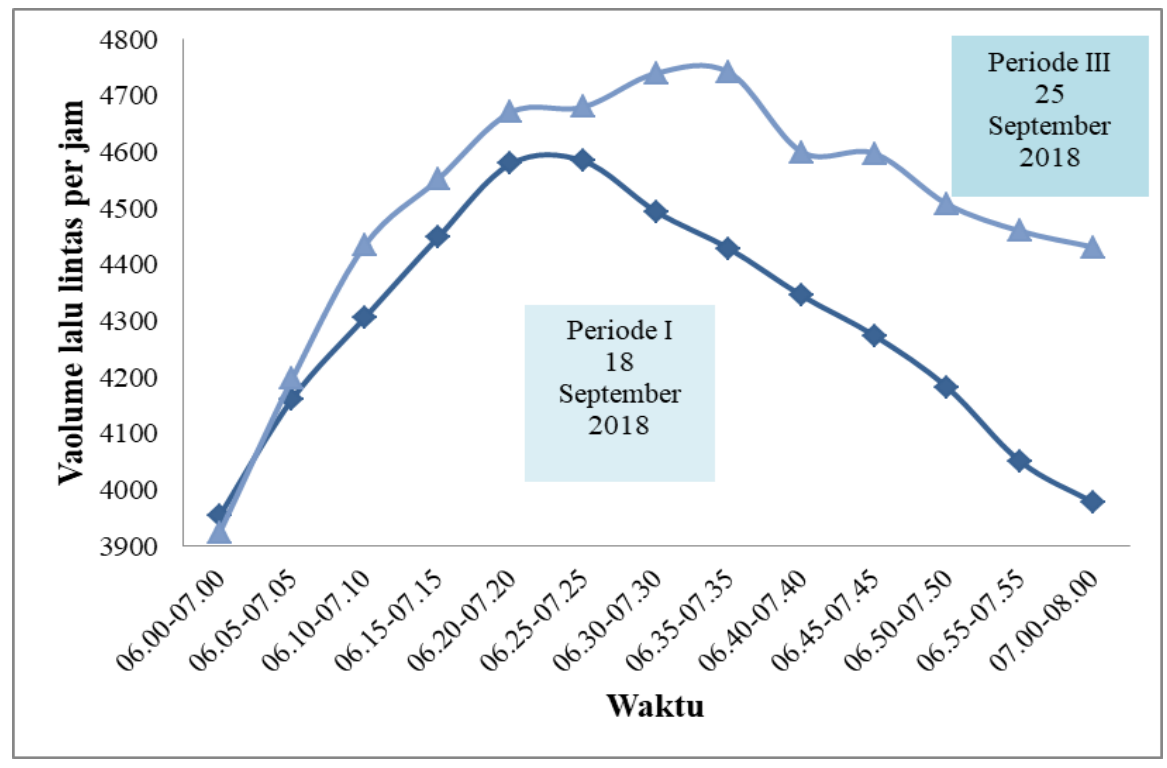

Gambar 3 Volume Lalu Lintas Periode I dan III 


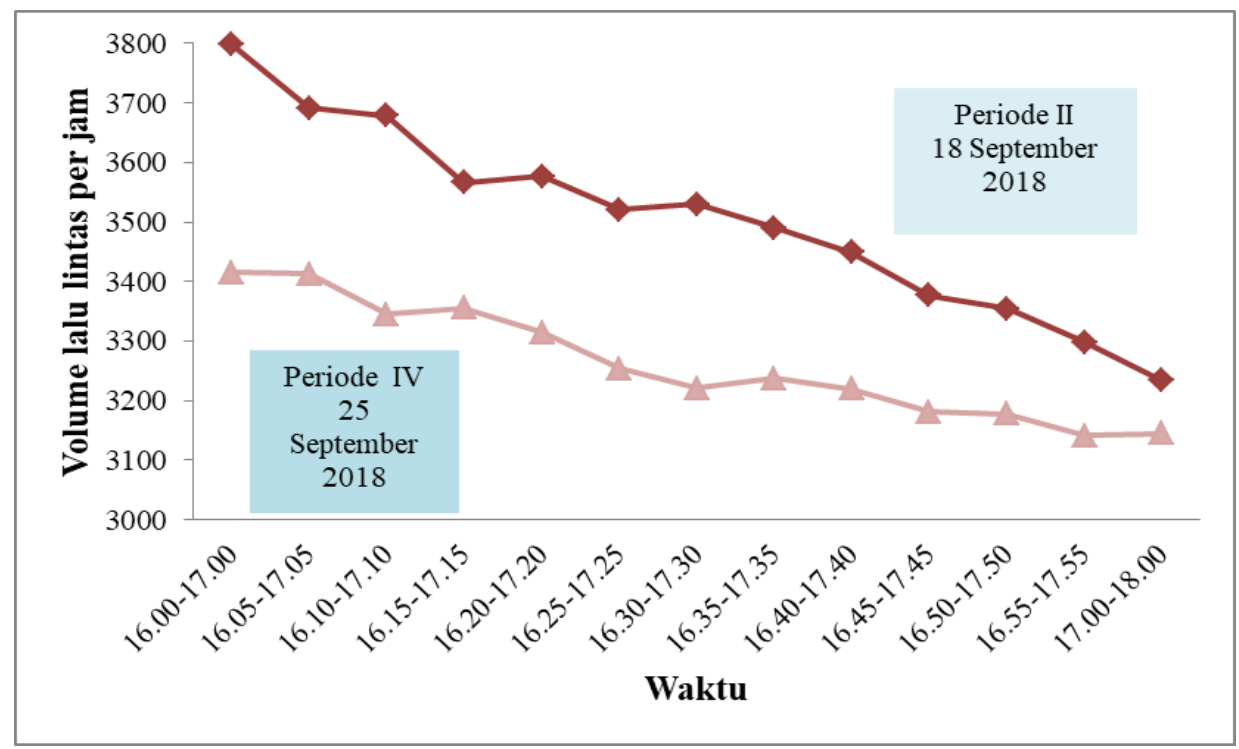

Gambar 4 Volume Lalu Lintas Periode II dan IV

Tabel 4 Kapasitas Simpang

\begin{tabular}{|c|c|c|c|c|}
\hline & Periode I & Periode III & Periode II & Periode IV \\
\hline Tipe persimpangan & 322 & 322 & 322 & 322 \\
\hline Kapasitas dasar Co (smp/jam) & 2700 & 2700 & 2700 & 2700 \\
\hline $\begin{array}{l}\text { Faktor penyesuaian berdasarkan rata-rata lebar } \\
\text { pendekat }(\mathrm{Fw})\end{array}$ & 0,89834 & 0,89834 & 0,89834 & 0,89834 \\
\hline Faktor penyesuaian median jalan utama $\left(\mathrm{F}_{\mathrm{M}}\right)$ & 1 & 1 & 1 & 1 \\
\hline $\begin{array}{l}\text { Faktor penyesuaian tipe lingkungan, hambatan } \\
\left.\text { samping, dan kendaraaan tak bermotor ( } F_{\text {RSU }}\right)\end{array}$ & 0,929 & 0,927 & 0,935 & 0,89 \\
\hline Faktor penyesuaian kelas $\operatorname{kota}\left(\mathrm{F}_{\mathrm{CS}}\right)$ & 0,94 & 0,94 & 0,94 & 0,94 \\
\hline Faktor penyesuaian kendaraan belok kiri $\left(\mathrm{F}_{\mathrm{LT}}\right)$ & 1,25 & 1,257 & 1,21 & 1,235 \\
\hline Faktor penyesuaian kendaraan belok kanan $\left(\mathrm{F}_{\mathrm{RT}}\right)$ & 1,089 & 1,089 & 1,089 & 1,089 \\
\hline Faktor penyesuaian arus jalur minor $\left(\mathrm{F}_{\mathrm{MI}}\right)$ & 1,078 & 1,072 & 1,038 & 1,032 \\
\hline Kapasitas sebenarnya (smp/jam) & 3114,03 & 3136,81 & 2896,21 & 2967,55 \\
\hline
\end{tabular}

Catatan: Periode I, pukul 06.00-08.00 dan Periode II, pukul 16.00-18.00 Tanpa Supeltas

Periode III, pukul 06.00-08.00 dan Periode IV, pukul 16.00-18.00 Ada Supeltas

\section{Kapasitas Simpang}

Kapasitas simpang merupakan arus maksimum yang dapat ditampung oleh suatu simpang. Secara ringkas proses analisis kapasitas simpang dapat dilihat pada Tabel 4. Berdasarkan Tabel 4 dapat diketahui bahwa terjadi peningkatan kapasitas simpang antara periode I dengan periode III, dan antara periode II dengan periode IV. Pada periode I, volume lalu lintas yang semula 3114,03 smp/jam menjadi 3136,81 smp/jam pada periode III. Sedangkan pada periode II, volume lalu lintas yang semula 2896,21 smp/jam meningkat menjadi 2967,55 smp/jam. Berdasarkan hasil tersebut dapat dikatakan bahwa keberadaan Supeltas memiliki dampak positif pada kinerja simpang, khususnya ditunjukkan oleh kapasitas simpang. Hal ini disebabkan oleh kontribusi Supeltas dalam mengurangi hambatan samping di area persimpangan. 


\section{Derajat Kejenuhan}

Derajat kejenuhan digunakan sebagai faktor utama dalam menentukan tingkat kinerja ruas jalan. Secara ringkas proses perhitungan derajat kejenuhan dapat dilihat pada Tabel 5. Berdasarkan Tabel 5 dapat diketahui terjadi peningkatan nilai DS pada periode I (Simpang tanpa Supeltas), yang awalnya sebesar 1,4 menjadi 1,51 pada periode III (dengan Supeltas). Hasil yang lain menunjukkan penurunan derajat kejenuhan pada periode IV (Simpang dengan Supeltas) menjadi 1,005 dari yang semula 1,31 pada periode II (tanpa Supeltas). Berdasarkan hasil tersebut dapat dikatakan bahwa Supeltas memiliki dampak positif pada kinerja persimpangan.

Nilai DS pada keempat periode lebih besar dari 1. Secara teoritis, nilai derajat kejenuhan tertinggi adalah 1, yang berarti bahwa jika nilai mendekati 1, kondisi lalu lintas telah mendekati batas kemampuan. Nilai DS lebih besar dari 1 dapat terjadi, yang disebabkan oleh beberapa faktor, misalnya tipe kendaraan yang berbeda-beda di lapangan yang harus dikonversikan ke dalam satuan mobil penumpang. Selain itu, disiplin penggunaan lajur jalan yang kurang diikuti menyebabkan pengguna sepeda motor melewati bahu jalan bahkan trotoar.

Tabel 5 Derajat Kejenuhan

\begin{tabular}{lrccc}
\hline & Periode I & Periode III & Periode II & Periode IV \\
\hline Volume (Q) (smp/jam) & 4584,20 & 4741,8 & 3792,3 & 3415,22 \\
Kapasitas (C) (smp/jam) & 3114,03 & 3136,81 & 2896,21 & 2967,55 \\
Derajat kejenuhan & 1,47 & 1,51 & 1,31 & 1,005 \\
\hline
\end{tabular}

\section{Tundaan}

Tundaan pada simpang terjadi karena terdapat pergerakan yang berbelok selain gerakan menerus yang saling memengaruhi. Selain itu, kondisi geometrik simpang ketika akan berbelok juga dapat menambah waktu perjalanan pengendara. Secara ringkas nilai parameter tundaan dapat dilihat pada Tabel 6.

Tabel 6 Tundaan

\begin{tabular}{lcccc}
\hline & Periode I & Periode III & Periode II & Periode IV \\
\hline $\mathrm{DT}_{1}($ det/pcu) & 36,422 & 36,422 & 36,422 & 15,24 \\
$\mathrm{DT}_{\mathrm{MA}}(\mathrm{det} / \mathrm{pcu})$ & 21,035 & 21,035 & 21,035 & 10,64 \\
$\mathrm{DT}_{\mathrm{MI}}(\mathrm{det} / \mathrm{pcu})$ & 166,41 & 166,41 & 166,41 & 54,14 \\
$\mathrm{DG}(\mathrm{det} / \mathrm{pcu})$ & 4 & 4 & 4 & 4 \\
$\mathrm{D}($ det/pcu$)$ & 40,422 & 4,422 & 40,422 & 19,24 \\
\hline
\end{tabular}

Catatan: Periode I, pukul 06.00-08.00 dan Periode II, pukul 16.00-18.00 Tanpa Supeltas Periode III, pukul 06.00-08.00 dan Periode IV, pukul 16.00-18.00 Ada Supeltas

Pada Tabel 6 terlihat bahwa tidak ada perubahan tundaan yang terjadi pada periode I dan periode III. Perubahan tundaan terjadi pada periode IV dengan penurunan tundaan dari 40,22 detik/smp menjadi 19,24 detik/smp. Pada kondisi lapangan, tundaan disebabkan banyaknya aktivitas kendaraan yang masuk dan keluar gang di area persimpangan yang menyebabkan kendaraan pada jalur utama harus berhenti untuk memberi kesempatan kepada kendaraan yang akan masuk atau keluar gang. 


\section{Peluang Antrian (QP)}

Peluang antrian dipengaruhi oleh perbandingan antara arus yang lewat dengan kapasitas simpang, yang dinyatakan dalam derajat kejenuhan. Secara ringkas hasil perhitungan peluang antrian (dalam \%) dapat dilihat pada Tabel 7.

Tabel 7 Peluang Antrian

\begin{tabular}{lcccc}
\hline & Periode I & Periode III & Periode II & Periode IV \\
\hline Batas atas (\%) & 97,78 & 97,78 & 97,78 & 80,34 \\
Batas bawah (\%) & 48,85 & 48,85 & 48,85 & 40,58 \\
\hline
\end{tabular}

Pada Tabel 7 dapat diketahui bahwa tidak ada perbedaan peluang antrian yang terjadi pada periode I, periode II, dan periode III. Perbedaan hanya terjadi pada periode IV, dengan penurunan peluang antrian dari 48,85\%-97,78\% menjadi 40,58\%-80,34\%. Hal ini mengikuti nilai DS yang jauh lebih besar dari 1, dan hanya pada periode IV saja nilai DS hampir sama dengan 1.

\section{KESIMPULAN}

Hasil studi ini menunjukkan bahwa kondisi simpang yang diamati sudah terlalu jenuh, baik pada kondisi dengan atau tanpa Supeltas. Dengan adanya Supeltas, diperoleh kapasitas sebesar 3136,81 smp/jam, dan derajat kejenuhan senilai 1,51.

Keberadaan Supeltas memiliki dampak positif pada kinerja simpang, khususnya pada kapasitas simpang. Hal ini ditunjukkan oleh peningkatan kapasitas simpang, dari 3114,03 smp/jam menjadi 3136,81 smp/jam. Meskipun demikian, terjadi peningkatan derajat kejenuhan juga di lokasi dengan Supeltas, yang disebabkan oleh peningkatan volume lalu lintas selain peningkatan kapasitas.

\section{DAFTAR PUSTAKA}

Direktorat Jenderal Bina Marga. 1997. Manual Kapasitas Jalan Indonesia. Bandung: Pusat Penelitian dan Pengembangan Jalan.

Hidayati, N., Liu, R., dan Montgomery, F., 2012. The Impact of School Safety Zone and Roadside Activities on Speed Behavior: The Indonesia Case. Procedia-Social and Behavior Science, 54 (1): 1339-1349.

Munawar, A. 2004. Manajemen Lalu Lintas Perkotaan. Yogyakarta: Penerbit Beta Offset. Mustikarani, W. dan Suherdiyanto. 2016. Analisis Faktor-Faktor Kemacetan Lalu Lintas di Sepanjang Jalan H. Rais A. Rahmad (Sui Jawi) Kota Pontianak. Jurnal Edukasi, 14 (1): 143-155.

Primasari, I. 2014. City Branding Solo sebagai Kota Wisata Budaya Jawa oleh Dinas Kebudayaan dan Pariwisata Kota Solo. Surakarta: Universitas Sebelas Maret. 
Rudatyo, W.S. dan Hafid Z. 2017. Kajian Yuridis terhadap Peran Serta Sukarelawan Pengatur Lalu Lintas (Supeltas) dalam Menciptakan Ketertiban Lalu Lintas di Surakarta. Surakarta: Universitas Islam Batik Surakarta.

Tamin, O.Z. dan Nahdalina. 1998. Analisis Dampak Lalu Lintas (Andalalin). Jurnal Perencanaan Wilayah dan Kota. Bandung: Institut Teknologi Bandung.

Wismabrata, M. 2017. Mulai Ramai, Ini 14 Titik Macet di Solo. (Online), (https://regional. kompas.com/read/2017/06/24/15211631/mulai-ramai-ini-14-titik-macet-di-solo, diakses 24 Juni 2017). 